\title{
Moriond Spirit Thriving after 25 Years
}

The 25th anniversary of the Rencontres de Moriond, the world-renowned international discussion meeting in particle physics, was celebrated at a reunion in Paris on 12 December 1991 in honour of Dr. Jean Trân Thanh Vân, the founder and organizer.

The now famous Rencontres de Moriond were born in a chalet in Moriond - a small mountain village in the French Alps - in 1966. The original idea of the founder, Jean Trân Thanh Vân of the CNRS Laboratory for Theoretical Physics and High Energies, Orsay, was both simple and unusual, namely to allow theoreticians and experimentalists in particle physics to meet in a relaxed and stimulating atmosphere to discuss their common interest. Furthermore, the Moriond meetings were especially designed to give young physicists the opportunity to present their results in an international context.

The success of the meetings was such that four years later, in 1970, the number of participants had increased from 20 to 80 and the venue had to be changed to an hotel in Meribel (Le Lac Bleu) where it remained for several years in an atmosphere as convivial as that of the Moriond chalet. The Rencontres acquired a new dimension at the same time by having a parallel meeting in biology (conceived and chaired by Kim Trân Thanh Vân), thereby creating a unique and stimulating meeting ground for physicists and biologists.

The present two-week format was adopted shortly afterwards, with one week devoted to electroweak interactions and the other to strong interactions. A meeting on astrophysics held at the same time as the electroweak session was created in 1981, along with a workshop on non-accelerator particle physics that takes place in January. Owing to the favourable conditions and the comprehensive coverage of scientific topics, participation increased to the point that the meetings moved in 1976 to their present venue, a hotel in Les Arcs.

Being myself a young physicist in these early years, I can testify that the Moriond experience was absolutely unique at the time. The informal and pleasant surroundings created ideal conditions for scientific exchange: an experimentalist would not hesitate discussing preliminary results with theoreticians. Likewise, a young theoretician would feel confident to talk about his latest work with senior colleagues and to submit ideas to experimentalists.

There are now four different sessions in particle physics requiring four different programme committees. Despite this, the Rencontres remain the personal enterprise of Jean Trân Thanh Vân who has ensured the continuity of the Moriond spirit for a quarter of a century. They are recognized as an international series, openly inspiring the creation of similar events where large experimental collaborations present for the first time their latest results. The American Physical Society includes them in its main list of conferences and an increasing number of American physicists participate.
I have had the privilege of collaborating with Jean for many years and have witnessed his multiple joys and multiple worries, and above all, his complete devotion which makes the Rencontres de Moriond the unique meeting we are all appreciate so much.

\section{A. Capella}

Laboratoire de Physique Théorique et Hautes Energies, Université Paris-XI

\section{Russian Academy Elects First President}

The 1st General Assembly of the new Russian Academy of Sciences held on 14 December 1991 elected Professor Youri Ossipov, former Director of the Institute of Mathematics and Mechanics of the Ural branch of the Academy of Sciences of the USSR, as President. Members and correspondents of both the Russian and the USSR Academies participated. The Russian government indicated that it will budget the Russian Academy's operations (comprising mainly some $95 \%$ of the USSR Academy's approximately 400 larger institutes and centres) for the first half of 1992 at a level equivalent to the 1991 level. It also hoped that western aid for fundamental research would be forthcoming, although agreement on a special international fund [EN 22 (1991) 166] has not been reached. Meanwhile, Russian institutes are bracing themselves for significant cut-backs over and above the on-going attrition of well-qualified staff.

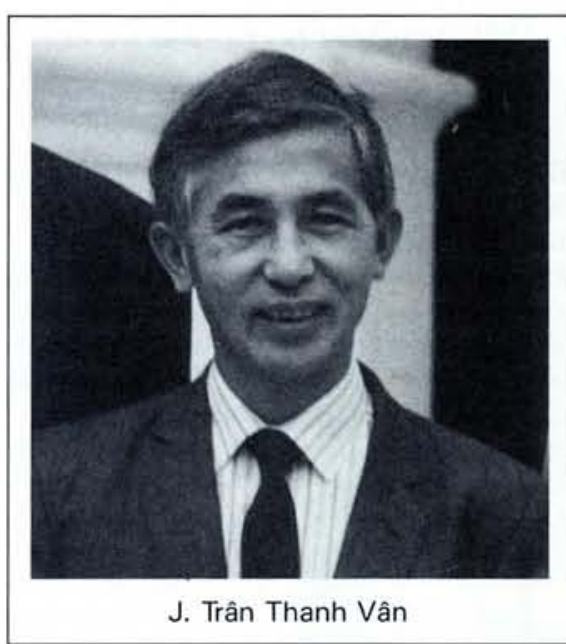

\section{Meetings Announcements}

6 - 10 April 1992

European Seminar in Telemedicine Athens Univ., Mikras Assias 75

Goudi GR-115 27 Athens

+30 (1) 7793273 or $7788199 / 7793273$ sotirio @ grathun1

A: 15 Mar $92 /$ limited to $35 /$ CEC

6- 13 May 1992

Phase Separation in Cuprate Superconductors: Int. School of Solid State Physics 3rd Workshop (Director: K.A. Müller)

G. Benedek, Dipt. di Fisica dell'Univ., Via Celoria, 16, 1-20133 Milan +39 (2) $2392352 / 2392414$ A: 29 Feb 91 / PP / 45 / \$US 700 - incl, board incl. proc. / INFM, CNR, UNESCO, ICS, IBM

6 - 10 July 1992

Marseilles, France PEH 92: Physique en Herbe 92: European Cong. of Young Physicists

A. Gargani, CRMC 2-CNRS, Campus de Luminy, Case 913, F-13288 Marseille Cédex 9 +33 () $91172808 / 91418916$ Ab: 1 Mar 92

7 - 10 July 1992 Nantes, France

ISFD-2: 2nd Int. Symp. on Domain Structure of Ferroelectrics \& Related Materials

R. Le Bihan, Fac. des Sciences,

Nantes Univ., F-44072 Nantes Cédex 03 +33 () $40373057 / 40293251$ Ab: 15 Mar $92 / \mathrm{PP}$

\section{UPPSALA UNIVERSITY \\ DEPARTMENT OF PHYSICS \\ Uppsala, Sweden}

\section{Lecturer in Physics especially Surface Physics}

The lecturer will participate in research and graduate teaching within the fields Physics of Metal Surfaces and/or Physics of Clusters. The research program includes electronic structure of surfaces and interfaces, adsorption on metal surfaces, catalytic reactions and properties of deposited clusters. The Lecturer will also participate in undergraduate teaching and course development.

Required qualifications are Ph.D. degree and experience of relevant research and of university undergraduate teaching. Research experience is of particularly high value.

The applications should be directed to the Vice Chancellor, University of Uppsala and received not later than February 3, 1992 at the following address:

The Registrar's Office, Uppsala University, Box 256, S-751 05 Uppsala, Sweden.

Detailed information and formal rules for application will be sent on request. For further information, please contact:

Prof. Nils Mårtensson, Department of Physics, Box 530, S-751 21 Uppsala, Sweden - tel. +4618183620 or 4618183558 , fax +46 18 183524 . 